American Journal of Applied Sciences 9 (1): 103-106, 2012

ISSN 1546-9239

(C) 2012 Science Publications

\title{
Theoretical Study of the Proton Transfer in Enaminones
}

\author{
Rita Sabah Elias \\ Department of Pharmaceutical Chemistry, College of Pharmacy, \\ University of Basrah, Iraq
}

\begin{abstract}
Problem statement: Hydrogen bonding has a vital rule to unrevealed the nature of many different interactions both in gas phase and condensed media thus it is one of the most important concepts in chemistry. Enaminoes with their ability to form intrahydrogen bonded cheated rings represent one of the suitable compounds to study such concept. Approach: The three possible tautomers of eneminones were fully optimized at several theoretical levels including B3LYP with the $6-31+G(d, p), 6-311++G(d, p)$ and aug-cc-pVDZ basis sets as well as MP2/6-311++G(d,p) level of theory. Then a search for the possible transition state between the two most stable tautomers; the ketamine and the enolimine was done at the B3LYP/6-311++G(d,p) level of theory. Results: The ketamine is the most stable while the diketo is the less stable within the tautomeric mixture and the proton transfer occurs through a transition state that is energetically resemble the enolimine tautomer. Conclusion: The interconversion of the tautomers is preferable in the enolimine $\rightarrow$ ketamine direction.
\end{abstract}

Key words: Proton transfer, intrahydrogen bonding, post hartree-fock, system enough, imaginary frequency, geometry optimized structures, tautomeric mixture, Transition State (TS)

\section{INTRODUCTION}

The term enaminone is used to indicate any compound containing the conjugated system $\mathrm{N}-\mathrm{C}=\mathrm{C}-$ $\mathrm{C}=\mathrm{O}$. It may be mono-enamine of 1,3-diketone or 3keto-ester: (Saeed et al., 2011). They are versatile synthetic intermediates that combine the ambident electrophilicity of enones with the ambident nucleophilicity of enamines. They are typical push-pull systems in which the amine group pushes and the carbonyl pulls electron density and have the ability to function both as ambident nucleophiles and as ambident electrophiles (Michael et al., 1999; Almazroa1 et al., 2004; Ruffino and Zanetti, 2009). The carbonyl group, conjugated with the enamine moiety, gives this system enough stability to be easily prepared, isolated and stored under atmospheric conditions at room temperature (Junior et al., 1999; Shawali, 2010). Enaminones are known to possess a variety of medicinal properties including anticonvulsant, antimalarial, antiinflamatory, antitumor and cardiovascular effects (Chaaban et al., 1979; Purnami et al., 2009). Enaminones are an important class of organic synthetic intermediates for the synthesis of a variety of heterocycles and pharmaceutical compounds. Their basic structural units, $\mathrm{N}-\mathrm{C}=\mathrm{C}-\mathrm{C}=\mathrm{O}$, are responsible for the synthesis of many therapeutic agents of both natural and synthetic sources, including taxol, anticonvulsants, anti-inflammatory agents and ducarmycin classes of anti-tumor agents, as well as quinoline antibacterial and quinoline antimalarial agents (Hogenkamp et al., 2007; Idafiogho et al., 2006; Ghandi and Jamea, 2011).

\section{MATERIALS AND METHODS}

Full geometry optimizations were carried out using Density Functional Theory (DFT) method with functional hybrid B3LYP with the 6-31+G(d,p), 6$311++G(d, p)$ and aug-cc-pVDZ basis sets. Post HatreeFock MP2 method was also used with $6-311++G(d, p)$ basis set. The search for imaginary frequencies that indicates the transition states was done by calculating the frequencies of the geometry optimized structures at the same level of theory used to the geometry optimization. No imaginary frequencies was found in the calculated spectra of the studied tautomers indicating a that the structures at a global minima, while the spectra of the transition states were characterized by a single imaginary frequency.

\section{RESULTS AND DISCUSSION}

Enaminones could exist as an equilibrium mixture of three tautomers namely ketoamine, enolimine and diketo. The optimized structures of the three 
tautomers at the B3LYP/aug-cc-pVDZ level of theory are shown in Fig. 1.

Due to the lack of crystallographic data about the structure of the ketamine tautomer its structure is calculated in this study at several levels of theory for comparison (Table 1).

The predicted bond angles and bond length at the B3LYP/6-31+G(d,p) level of theory are identical to those calculated at the same level in a previous study (Gilli et al., 2000; Eberlin et al., 1990). Table 1 shows that the calculated properties depend on the theoretical level used for optimization but in general the results are almost indicate a strong conjugation within the sexmembered chelated ring of the molecule. This is obvious from the deviation of the calculated bond lengths from the values of the pure single or double bonds. The calculated $\mathrm{C}=\mathrm{O}$ and $\mathrm{C}=\mathrm{C}$ bonds at the B3LYP/6-311++G(d,p) level are 1.235 and $1.371 \AA$ and are longer than their values in aliphatic ketones and ethylene which are while the bond C-C and C-N are shorter than their value in alkanes and aliphatic amines.

With exception to the MP2 case which predicted the ebolimine and the dike to tautomers as degenerate species with total energies -245.8598864 and 45.8608857 a.u. respectively (Table 2 ), the predicted total energies suggest that the embolic forms (the ketamine and enolimine) are more stable than the diketo. This is in agreement with the experimental studies. This could be explained on the basis that the enolic forms are stabilized by the conjugated intrahydrogen bonded chelated ring. Tabel 2 shows that within the enolic forms the hetamine is the most stable.

The total energies calculated for the ketamine, enolimine and diketo tautomers at the CBS-QB3 method are -247.3616027, -247.3493333 and 247.3365632 respectively. Accordingly the proton transfer calculations in this study are confined to the ketamine and enolimine tautomers only.

The infrared spectra of the ketamine are shoen and interpreted in Table 3. The number of frequency modes (24) is in consistent with that predicted by the rule $3 \mathrm{~N}-6$. The $\mathrm{N}-\mathrm{H}$ stretching frequencies are calculated to be 3704 and $3471 \mathrm{~cm}^{-1}$ for the free and the intrahydrogen bonded N-H groups respectively. This in agreement with finding that hydrogen bonded groups have frequencies at lower wavenumbers compared to those of free groups (Kiss et al., 2000). With exception of the amni group frequencies which are over istimated at the B3LYP/6-311++G(d,p) level, the predicted other frequencies are within the experimental ranges.

Proton transfer: Figure 2 traces the gradual structural changes as the ketamine tautomer transferred to the inolimine by a proton transfer through the Transition State (TS) as follows.

The length of the carbonyl group (calculated at B3LYP/6-311++G(d,p) level of theory) changes from $1.235 \AA$ in the ketamine through $1.292 \AA$ in the TS to $1.322 \AA$ in the enolimine. The length of the imino group changes from $1.343 \AA$ in the ketamine through $1.310 \AA$ in the TS to $1.294 \AA$ in the enolimine. In the same time the bonds $\mathrm{C} 1-\mathrm{C} 2$ and $\mathrm{C} 2-\mathrm{C} 3$ changes from approximately single and double bonds respectively to approximately double and single bond through intermediate values on going from the ketamine to the enolimine. The bonds between transferred proton and the oxygen and nitrogen atoms changed in the direction of the reaction coordinates. In the ketamine it is bonded to the nitrogen atom through a $1.017 \AA$ bond, while in the transition state this linkage becomes $1.310 \AA$ and the proton being in the mid distance between the nitrogen and the oxygen atoms. Finally, in the enolimine the N-H bond break and O-H bond with a length of $1.009 \AA$ is formed. It worthy to note from Fig. 2 that the bond lengths of C-O and C-N in the TS are almost similar with values 1.292 and $1.310 \AA$. This is also true for the bonds $\mathrm{C} 1-\mathrm{C} 2$ and C2-C3.

To ascertain that the intermediate structure (TS) is a transition state the search for the single imaginary frequency is done by calculating the frequencies at the same level of theory and found that the calculated frequencies of the TS species contains a signal at -1196 $\mathrm{cm}^{-1}$ which indicates the presence of a transition state. From Figure 2 it clear that the transition state is near the enolimine as the stabilization energy between this tautomer and the transition state is $7.3 \mathrm{~kJ} . \mathrm{mol}^{-1}$ only. In contrast the stabilization energy with respect to the ketoamine is $41.4 \mathrm{~kJ}^{\mathrm{mol}}{ }^{-1}$. The calculated total energies of the species involved in the proton transfer at different levels of theory are gathered in Table 3.

From Table 4 it is clear that the calculated energies depend on the theoretical level used.

Figure 3 sketches the transition process showing the relative energies of the different species involved in the process. 


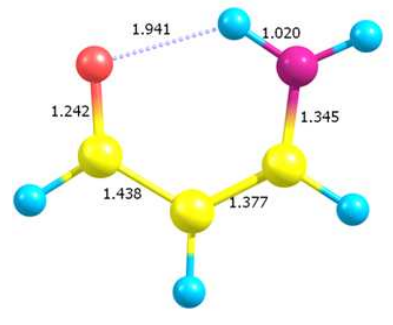

ketamine tautomer

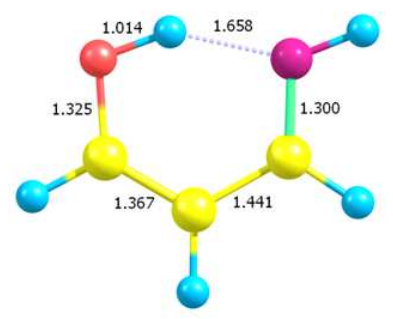

Enolimine tautomer

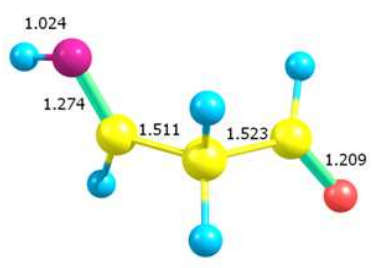

Diketo tautomer

Fig. 1: The optimized structures of enaminon tautomers at the B3LYP/aug-cc-pVDZ level of theory

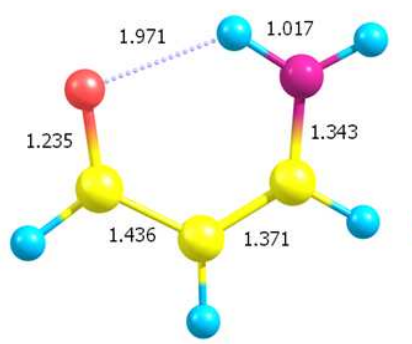

ketamine

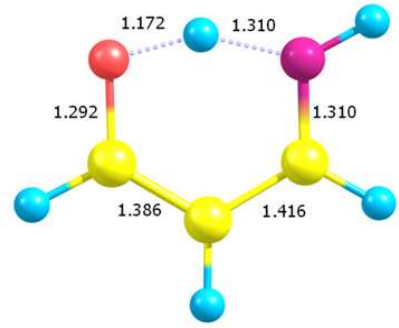

Transition State (TS)

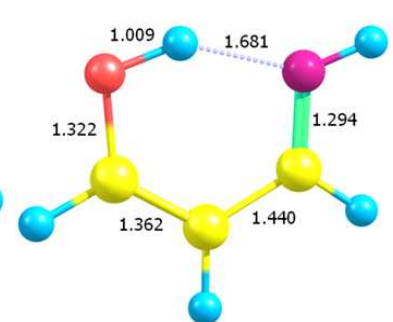

Enolimine

Fig. 2: Proton transfer process in eneminones

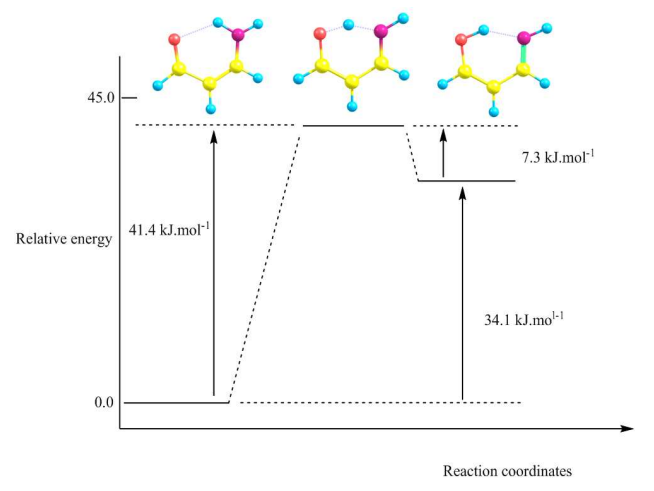

Fig. 3: Stabilization energies for the proton transfer process in enaminones

Table 1: Calculate structural properties of the ketamine tautomer at several levels of theory

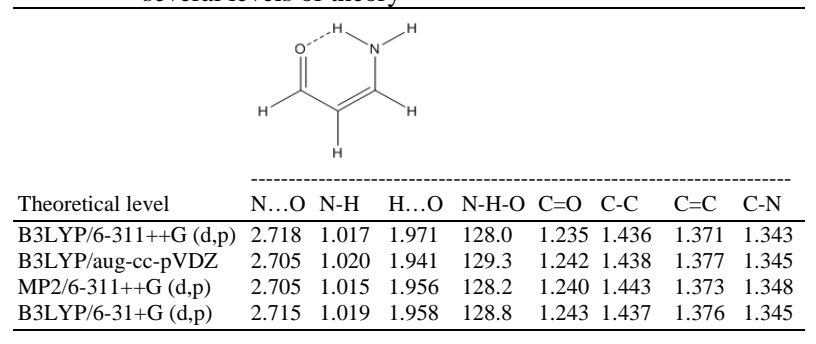

Table 2: Total energies (a. u.) of the tautomers calculated at different levels of theory

\begin{tabular}{llll}
\hline Theoretical level & ketamine & Enolimine & Diketo \\
\hline B3LYP/6-311++G(d,p) & -247.3701168 & -247.3571141 & -247.345436 \\
B3LYP/Aug-cc-pVDZ & -247.3293542 & -247.3174195 & -247.3044349 \\
MP2/6-311++G(d,p) & -245.8759891 & -245.8598864 & -245.8608857 \\
CBS-QB3 & -247.3616027 & -247.3493332 & -247.3365632 \\
\hline
\end{tabular}

Table 3: Calculated infrared frequencies of the ketamine tautomer at B3LYP/6-311++G (d,p)

\begin{tabular}{|c|c|c|c|}
\hline Mode no. & Frequanc & Irintensity & Assignments \\
\hline 24 & 3704 & 99.27 & $(\mathrm{~N} 1-\mathrm{H} 2+\mathrm{N} 1-\mathrm{H} 1)$ stretching \\
\hline 23 & 3472 & 60.33 & (N1-H1 + C1-H2 stretching \\
\hline 22 & 3203 & 6.03 & $(\mathrm{C} 1-\mathrm{H} 2+\mathrm{N} 1-\mathrm{H} 2)$ stretchin \\
\hline 21 & 3160 & 9.78 & $(\mathrm{C} 1-\mathrm{H} 3+\mathrm{C} 2-\mathrm{H} 4)$ stretching \\
\hline 20 & 2925 & 143.63 & C3-H5 stretching \\
\hline 19 & 1702 & 246.82 & $(\mathrm{C} 13-\mathrm{O} 1+\mathrm{C} 1-\mathrm{N} 1)$ stretching \\
\hline 18 & 1651 & 263.64 & $\mathrm{NH}_{2}$ bending \\
\hline 17 & 1547 & 255.36 & $\mathrm{~N} 1-\mathrm{H} 2$ bending $+(\mathrm{C} 1-\mathrm{C} 2+\mathrm{C} 2-\mathrm{C} 3)$ stretching \\
\hline 16 & 1474 & 9.06 & $(\mathrm{C} 1-\mathrm{C} 3+\mathrm{C} 2-\mathrm{H} 4)$ in-plane bending \\
\hline 15 & 1406 & 15.25 & C3-H5 in-plane bending \\
\hline 14 & 1325 & 137.16 & $(\mathrm{C} 1-\mathrm{H} 3+\mathrm{N} 1-\mathrm{H} 1)$ in-plane bending \\
\hline 13 & 1173 & 4.01 & $(\mathrm{C} 13-\mathrm{H} 3+\mathrm{C} 2-\mathrm{H} 4)$ in-plane bending \\
\hline 12 & 1119 & 2.07 & $(\mathrm{C} 2-\mathrm{H} 4+\mathrm{N} 1-\mathrm{H} 2)$ in-plane bending \\
\hline 11 & 1027 & 3.49 & (C3-H5 + C1-H3) out-of-plane bending \\
\hline 10 & 993 & 1.33 & $(\mathrm{C} 3-\mathrm{H} 5+\mathrm{C} 1-\mathrm{H} 3)$ out-of-plane bending \\
\hline 9 & 980 & 41.41 & C2-C3 stretching \\
\hline 8 & 939 & 18.91 & $\mathrm{C} 1-\mathrm{C} 2-\mathrm{C} 3$ bending \\
\hline 7 & 766 & 15.17 & $(\mathrm{C} 2-\mathrm{H} 4+\mathrm{N} 1-\mathrm{H} 1)$ out-of-plane bending \\
\hline 6 & 749 & 71.17 & $(\mathrm{~N} 1-\mathrm{H} 2+\mathrm{C} 2-\mathrm{H} 4)$ out-of-plane bending \\
\hline 5 & 461 & 5.52 & (C3-H5 + N1-H5) out-of-plane bending \\
\hline 4 & 435 & 40.46 & (N1-H1+ N1-H2) out-of-plane bending \\
\hline 3 & 271 & 72.99 & $(\mathrm{C} 3-\mathrm{H} 5+\mathrm{N} 1-\mathrm{H} 2)$ out-of-plane bending \\
\hline 2 & 259 & 9.97 & O1-H1 stretching \\
\hline 1 & 258 & 73.99 & $\mathrm{~N} 1-\mathrm{H} 2$ out-of-plane bending \\
\hline
\end{tabular}


Table 4:Energies of the species involvet in proton transfer process in enaminones calculated at several theoretical levels

\begin{tabular}{llll}
\hline Theoretical level & Enone & Enol & Transition state \\
\hline B3LYP/6-31+G (d,p) & -247.3123530 & -247.2995960 & -247.2976088 \\
B3LYP/6-31++G (d,p) & -247.3125329 & -247.2997625 & -247.2977806 \\
B3LYP/6-311G (d,p & -247.3616027 & -247.3493332 & -247.3464642 \\
B3LYP/6-311+G (d,p & -247.3700201 & -247.3570366 & -245.8502458 \\
B3LYP/6-311++G (d,p & -247.3701168 & -247.3571141 & -247.3543292 \\
\hline
\end{tabular}

The same trends are found when the study of the proton transfer is conducted on a phenyl substituted enaminone. The introducing a phenyl ring to the enaminone chelated ring reduces the $\mathrm{C}=\mathrm{O}$ bond length from 1.292-1.250 $\AA$ due to the conjugation between the two groups. The other effect of introducing the phenyl ring is that it reduces the relative energies between the ketoamine and the enolimine with respect to the transition satate. The stabilizing energies with respect to the ketamine and the enolimine are 38.9 and 5.1 $\mathrm{kJ} . \mathrm{mol}^{-1}$ compared to 41.4 and $7.3 \mathrm{~kJ} \mathrm{~mol}^{-1}$ for the case of the substituted enaminone. This implies that the proton transfer in aromatic enaminones is more feasible than non substituted ones.

We try to study the proton transfer process in a methyl substituted enaminone at DFT and MP2 methods with several basis sets but in all cases the transition state converged to the enolimine.

\section{CONCLUSION}

The ketamine is the most stable tautomer in the equilibrium mixture of the enaminones while the diketo is the less stable. The interconversion between theketamine and the enolime tautomers is preferable in the enolimine $\rightarrow$ ketamine direction. In addition the presence of an aromatic substituent makes the proton transfer in these compounds mare feasible by reduction of the stabilization energy between the tautomers and the transition state.

\section{REFERENCES}

Almazroa1, S., M.H. Elnagdi and A.M.S. El-Din, 2004. Studies with enaminones: The reaction of enaminones with aminoheterocycles. A route to azolopyrimidines, azolopyridines and quinolines. J. Heterocyclic Chem., 41: 267-272. DOI: 10.1002/jhet.5570410219

Chaaban, I., J.V. Greenhill and P. Akhtar, 1979. Enaminones in the mannich reaction. Part 2. Further investigations of internal mannich reactions. J. Chem. Soc. Perkin Trans., 1: 15931596. DOI: 10.1039/P19790001593

Eberlin, M.N., Y. Takahat and C. Kasscheres, 1990. The use of AM1 in structural analyses of primary and secondary enaminones. Theochem, 207: 143156. DOI: $10.1016 / 0166-1280(90) 85019-j$
Ghandi, M. and A.H. Jamea, 2011. Pyridine-mediated, one-pot, stereoselective synthesis of acyclic enaminones. Tetrahedron Lett., 52: 4005-4007. DOI: 10.1016/j.tetlet.2011.05.112

Gilli, P., V. Bertolasi, F. Ferretti and G. Gilli, 2000. Evidence for intramolecular $\mathrm{N}-\mathrm{H}$... O resonanceassisted hydrogen bonding in $\beta$-Enaminones and related heterodienes. A combined crystalstructural, IR and NMR spectroscopic, and quantum-mechanical investigation. J. Am. Chem. Soc., 122: 10405-10417. DOI: 10.1021/ja000921

Hogenkamp, D.J., T. B.C. Johnstone, J.C. Huang, W.Y. $\mathrm{Li}$ and M. Tran et al., 2007. Enaminone amides as novel orally active $\mathrm{GABA}_{\mathrm{A}}$ receptor modulators. J. Med. Chem., 50: 3369-3379. DOI: 10.1021/jm070083v

Idafiogho, I.O., K.V.V. Ananthalakshmi and S.B. Combian, 2006. Anticonvulsant evaluation and mechanism of action of benzylamino enaminones. Bioorg. Med. Chem., 14: 5266-5272. DOI: 10.1016/j.bmc.2006.03.049

Junior, A.W., A.R.M. Oliveira, C.J. de Chunha, F. Simonelli and F.A. Marques, 1999. Synthesis of enaminones withstationary stereochemistry. J. Braz. Chem. Soc., 10: 369-374. DOI: 10.1590/S0103-50531999000500006

Kiss, J.T., F. Felfoldi and I. Plainko, 2000. Hydrogen bonding interactions in $\alpha$-substituted cinnamic acid ester derivatives studied by FT-IR spectroscopy and calculations. Vibrational Spectroscopy, 22: 6373. DOI: 10.1016/S0924-2031(99)00054-5

Michael, J.P., C.B. De Koning, D. Gravestock, G.D. Hosken and A.S. Howard et al., 1999. Enaminones: Versatile intermediates for natural product synthesis. Pure Applied Chem., 71: 979988.

Purnami, S.W., A. Embong, J.M. Zain and S.P. Rahayu, 2009. A new smooth support vector machine and its applications in diabetes disease diagnosis. J. Comput. Sci., 5: 1003-1008. DOI: 10.3844/jcssp.2009.1003.1008

Ruffino, B and M. Zanetti, 2009. Adsorption study of several hydrophobic organic contaminants on an aquifer material. Am. J. Environ. Sci., 5: 508-516. DOI: 10.3844/ajessp.2009.508.516

Saeed, B.A., R.S. Elias and E.A. Musad, 2011. Intrahydrogen bonding and transition states between enol and enethiol tautomers beta thioxoketones. Am. J. Applied Sci., 8: 762-765. DOI: 10.3844 /ajssp.2011.773.776

Shawali, A.S., 2010. Synthesis, reactions and antitumour screening of new enaminones. J. Chem. Res., 34: 630-634. 